\title{
PREFERÊNCIA PELA LIQUIDEZ, FINANCEIRIZAÇÃO E EFEITOS DE PROPAGAÇÃO: DA NÃO NEUTRALIDADE DA MOEDA Å NÃO NEUTRALIDADE DA FINANÇA
}

\begin{abstract}
Alain Herscovici ${ }^{a}$
aProfessor titular do Departamento de Economia da Universidade Federal do Espírito Santo (UFES), coordenador do Grupo de Estudo em Macroeconomia (GREM) do Programa de Pós-Graduação em

Economia da UFES, e bolsista de produtividade do CNPq. Vitória, ES, Brasil. Website pessoal: https://herscovicieconomics.weebly.com/. ORCID: https://orcid.org/0000-0002-0378-7561.
\end{abstract}

Recebido em 29 novembro 2018

Aceito em 05 maio de 2020

RESUMO: A crítica radical que Keynes faz à teoria dos fundos de empréstimos (TFE) revela a ruptura epistemológica entre a economia keynesiana e a economia neoclássica. Neste trabalho, estudarei a natureza dessa ruptura, mais especificamente no que diz respeito aos diferentes componentes da preferência pela liquidez e aos mecanismos a partir dos quais a incerteza se propaga nas diferentes esferas da economia. A partir dos trabalhos de Kahn e de Cardim de Carvalho, demonstrarei porque à não neutralidade da moeda é preciso acrescentar a não neutralidade do sistema financeiro. Na medida em que a atuação dos agentes se explica por meio de uma teoria da escolha dos ativos, mostrarei como a finança especulativa constitui um ativo específico e como ela exerce seus efeitos de propagação sobre a determinação da taxa de juros e, consequentemente, sobre o setor "real". Em uma primeira parte, analisarei os fundamentos da crítica que Keynes faz à teoria dos fundos de empréstimos. Numa segunda parte, estudarei, a partir dos trabalhos de Cardim de Carvalho, as relações entre a preferência pela liquidez, a taxa de juros e a finança especulativa.

PALAVRAS-CHAVE: taxas de juros; sistema financeiro; preferência pela liquidez.

CLASSIFICAÇÃO JEL: E12; B41.

Correspondência para: Alain Herscovici

Contato: alhersco.vix@terra..com.br 


\title{
LIQUIDITY PREFERENCE, FINANCIALIZATION, AND SPILLOVER EFFECT: FROM MONEY NON- NEUTRALITY TO FINANCE NON- NEUTRALITY
}

\begin{abstract}
Keynes's radical critique of the Loan Funds Theory reveals the epistemological rupture between Keynesian and Neoclassical Economics. In this paper, I will study the nature of this rupture, specifically concerning the different components of the liquidity preference and the mechanisms through which uncertainty propagates into the different spheres of the economy. Based upon Kahn's and Cardim de Carvalho's works, I will explain why, as money, the financial system is also not neutral, as to how it affects the determination of the interest rate and the productive sector. In the first part of the text, I will analyze the fundamentals of Keynes's critique of the Loan Funds Theory. In the second part, I will study, from the perspective of Cardim de Carvalho's works, the relationship between liquidity preference, interest rate, and speculative finance.
\end{abstract}

KEYWORDS: interest rate; financial system; liquidity preference. 


\section{INTRODUÇÃO*}

Em um artigo de síntese, Cardim de Carvalho escrevia que "[u]ma economia monetária não pode ser redutível, nem ao_longo prazo, a uma economia real” (CARVALHO, 1992a, p. 171). Em seu livro de 2016, ele afirma novamente que, segundo Keynes, "[r]eal variables were not sufficient to describe neither short or long term equilibrium positions" (CARVALHO, 2016, p. 3). Essa característica constitui um dos principais fundamentos da "revolução keynesiana", ou seja, da ruptura epistemológica à qual corresponde a Teoria Geral (TG) de Keynes.

No presente trabalho, acrescentarei apenas que essa diferenciação entre economia real e economia monetária (de produção) torna necessária uma redefinição da natureza econômica das atividades ligadas às finanças, assim como do papel assumido pelo sistema bancário: nesse sentido, após ter definido as principais características da abordagem pós-keynesiana, estudarei os efeitos de propagação (spillover effects) que a finança pode exercer sobre o setor produtivo e a taxa de juros.

Na obra de Cardim, esse tema aparece em vários trabalhos:

i) "Again, the debate allowed Keynes to refine his analysis by making clear the financial side of his principle of effective demand" (CARVALHO, 1996, p. 325-326). Da mesma maneira que a moeda não é neutra, a finança também não é neutra: esses dois ativos influenciam a demanda efetiva, ou seja, as variáveis "reais".

ii) O surgimento de novos produtos financeiros próprios à financeirização da economia "(...) reduces the horizon of expectations in the financial markets with some impact on the financing of longer-term activities, as argued below" (CARVALHO, 1997, p. 481). A finança especulativa prejudica o investimento produtivo - ligado, por natureza, ao longo prazo -, enfraquece o circuito finance/funding e se traduz por uma fragilidade financeira, no sentido minskiano. É preciso redefinir o papel do sistema bancário, assim como questionar sua suposta "neutralidade":

The same financial structures that allow productive investment and capital accumulation, and economic growth, to reach the levels characteristic of modern capitalist economies are also those where fragilities are accumulated that ultimately cause deep crises, such as the one that began in the U.S. economy in 2007 and has since spread throughout most of the world. (CARVALHO, 2016, p. 306)

* Quero agradecer os pareceristas da revista; suas observações me permitiram definir melhor a problemática e elaborar análises mais completas e aprofundadas. Obviamente, sou inteiramente responsável pelas teses defendidas neste trabalho e pelas interpretações propostas. 
Essa não neutralidade da finança amplia a crítica em relação à economia neoclássica: esta nega a existência de assimetrias de informação e. consequentemente, a existência da especulação financeira (FAMA, 1998; MALKIEL, 2003), tentando manter a primazia da economia real a partir da hipótese do valor fundamental dos títulos financeiros (HERSCOVICI, 2019).

A partir do momento que, na abordagem pós-keynesiana, a atuação dos agentes é concebida como uma teoria da escolha dos ativos, não é possível, como o faz a análise neoclássica, reduzir a atividade financeira a uma simples intermediação cuja função consiste apenas em implementar o investimento produtivo a partir da poupança (CARVALHO, 2012, p. 201). A tese defendida neste paper pode ser formulada da seguinte maneira: da mesma maneira que a análise pós-keynesiana reconhece que a moeda influencia o setor real, a finança também exerce seus efeitos sobre esse setor. Isso constitui mais uma divergência em relação à economia neoclássica, a qual refuta a existência da finança especulativa e das assimetrias da informação, para afirmar a primazia do real em relação ao monetário e ao financeiro.

Em uma primeira parte do texto, estudarei os elementos que fundamentam a ruptura introduzida por Keynes no que diz respeito à taxa de juros, à sua natureza e aos diferentes componentes da demanda por moeda. Mostrarei, a partir de uma formalização simples, porque Keynes refuta a teoria dos fundos de empréstimos (TFE) e, consequentemente, o conjunto da arquitetura da macroeconomia neoclássica. Em uma segunda parte, definirei a finança especulativa e mostrarei como ela exerce seus efeitos sobre os setores produtivos da economia; utilizarei vários elementos presentes na obra de Cardim de Carvalho para ressaltar a importância do papel do sistema bancário nessa dinâmica especulativa e mostrarei em que medida essa análise é incompatível com as hipóteses e os resultados da escola neoclássica, no que diz respeito ao papel dos bancos e à própria natureza econômica da finança (CARVALHO, 2012, 2005).

\section{KEYNES E A TFE: OS FUNDAMENTOS DA CRÍTICA}

\subsection{OS DETERMINANTES DA TAXA DE JUROS}

No capítulo 14 da TG, Keynes (1990[1936]) ressalta os limites, ou seja, os problemas de coerência interna da teoria clássica, no que diz respeito à TFE. A crítica feita por Keynes é diretamente ligada às modalidades de determinação da taxa de juros e, consequentemente, à natureza da poupança. Para os clássicos, a demanda por fundos (ou por recursos) é assimilada ao investimento; simetricamente, a oferta de fundos corresponde à poupança (Ibid., p. 143). A taxa "natural” é a taxa que corresponde à igualação entre a demanda e a oferta de fundos, para uma situação de pleno emprego. 
Esse raciocínio parte dos seguintes pressupostos:

i) Em nível agregado, a taxa de juros é determinada endogenamente pela demanda e pela oferta de fundos (CARVALHO, 1996, p. 319).

ii) $\mathrm{Na}$ tradição marshalliana, o investimento, ou seja, a demanda por uma determinada quantidade de capital, corresponde à demanda por fundos, e a taxa de juros é o preço pago pelo uso do capital em qualquer mercado (KEYNES, 1990[1936], p. 143). Ela é concebida como a taxa de aluguel do capital e é obrigatoriamente igual à taxa de lucro.

iii) Nessa perspectiva, por definição, a poupança financia o investimento. Assim, a poupança é concebida como um mecanismo real, no sentido de não monetário. ${ }^{1}$

A taxa de juros representa o prêmio pela espera, pelo fato de renunciar ao consumo presente; finalmente, essa taxa de juros natural representa a taxa que permite igualar investimento e poupança a um nível que corresponde ao pleno emprego, no sentido de não haver desemprego involuntário. No âmbito deste trabalho, mostrarei como e porque Keynes refuta esses resultados.

Para Keynes, a demanda e a oferta de fundos determinam a taxa de juros a partir do momento que a renda é constante (Ibid., p. 145); apenas nessas condições, é possível determinar endogenamente a taxa de juros a partir da TFE. No entanto, uma variação do investimento é incompatível com a fato de a renda permanecer constante (Ibid., p. 145 e 146): a partir do momento em que existe o efeito multiplicador, a qualquer variação do investimento corresponde uma variação da renda: na TG, "[i]ncome, thus, was the adjusting variable charged with the task of equilibrating investment and saving decisions of individuais, and the way it did so was denominated the multiplier" (CARVALHO, 1996, p. 314).

$\mathrm{Na}$ teoria clássica, a taxa de juros é a recompensa pela espera, no que diz respeito ao consumo. Na tradição de Mills e Jevons, o ser racional seria dotado de uma preferência pelo consumo presente: a taxa de juros seria a recompensa para ele adiar o consumo presente. É interessante observar que, a partir de tal perspectiva, a poupança é uma escolha intertemporal de consumo: nos modelos neoclássicos de crescimento oriundos do modelo canônico de Solow (1956), a poupança representa um aumento do consumo futuro. De fato, apenas se a renda permanecer constante, à um aumento

A concepção de Hayek (2009[1950]) é parecida; este autor considera que a poupança é um desvio de produção, segundo seus próprios termos. Cardim (CARVALHO, 2012) mostra que, se essa concepção corresponde à uma economia de escambo ("economia do trigo"), ela não pode ser aplicada à uma economia monetária de produção na qual a moeda não é neutra e na qual existem ativos especulativos. 
da poupança atual corresponde uma diminuição do consumo atual, um aumento do investimento e, consequentemente, um aumento do consumo futuro.

No seio da construção neoclássica, a TFE cumpre uma dupla função: (a) é uma outra forma de expressar a Lei de Say (PETRI, 1998); o fato de a poupança financiar o investimento significa que, em nível agregado, toda a renda distribuída nas atividades de produção corresponde, direta ou indiretamente, aos gastos efetuados na totalidade da economia; (b) ela parte do pressuposto de que existe uma relação monotônica entre a taxa de juros e o investimento; tal relação permite explicar as modalidades de ajustamento para a posição de equilíbrio e remete diretamente à problemática da natureza do capital² (HERSCOVICI, 2013).

De fato, no modelo neoclássico, investimento e poupança são determinados endogenamente, a partir de variáveis reais: "[i]ncome, thus, equilibrium rate of interest depended, for orthodox theory, on thrift (that determined the propensity to save) and productivity (that limited the interest that could be paid by the marginal investment project)" (CARVALHO, 1996, p. 314).

As divergências entre os dois modelos (aquele exposto na TG e o modelo neoclássico) podem ser formalizadas da seguinte maneira:

$$
I=\varphi 1[e-r]
$$

$\operatorname{com} \varphi_{1}^{\prime}>0$

$$
\mathrm{S}=\varphi_{3}(\mathrm{Y})
$$

$\operatorname{com} \varphi_{3}^{\prime}>0$

Em (1), e representa a eficiência marginal do capital; $r$ representa a taxa de juros; I e $\mathrm{S}$, respectivamente, correspondem ao investimento e à poupança e $\mathrm{Y}$, à renda.

São duas equações ${ }^{3}$ e três incógnitas $(e, r$ e $Y)$; logo, não é possível resolver esse sistema. Em outras palavras, como afirma Keynes, não é possível determinar simultaneamente a taxa de juros, a eficiência marginal do capital e a renda.

2 Para uma apresentação sintética da controvérsia do capital, ver Pasinetti (1997) e Cohen e Harcourt (2003).

3 Essa formalização se inspira em Vercelli (1991, p. 184). 
A solução clássica consiste em exogeneizar a renda; nesse caso, a renda é determinada na esfera real, a partir de uma função de produção agregada bem comportada, na qual existe a substitutibilidade perfeita dos fatores de produção. A taxa de juros é determinada pela TFE; na tradição clássica, a taxa de juros é igual à taxa de lucro e à produtividade marginal do capital. A neutralidade da moeda é dupla: por um lado, a moeda não afeta a renda e, por outro lado, está tendo uma determinação real (e não monetária) da taxa de juros.

No sistema keynesiano, ao contrário, existe uma determinação exógena da taxa de juros (VERCELLI, 1991, p. 184; PASINETTI, 1997, p. 212). As implicações são as seguintes:

i) A TFE deixa de ser explicativa, já que ela não permite determinar a taxa de juros de equilíbrio.

ii) A exogeneidade da taxa de juros se explica a partir de sua determinação monetária e financeira, ou seja, a partir da função de reserva de valor da moeda.

iii) A partir desse sistema simples de equações, é possível deduzir que a renda é determinada pela taxa de juros, ou seja, por uma variável monetária, no sentido precedentemente definido; isso é sinônimo de não neutralidade da moeda.

Os mecanismos de ajustamento que permitem passar da posição de desequilíbrio para a posição de equilíbrio são igualmente diferentes. No âmbito da análise de Keynes na TG, o ajustamento se implementa a partir de uma variação da renda, pelo viés do efeito multiplicador: ex-post, poupança e investimento globais são iguais. À variação da renda produzida pela variação inicial do investimento corresponde uma variação da poupança, de tal maneira que o incremento da poupança seja igual ao incremento do investimento: "[s] avings are created by investment since they are allocations of income generated by the investment activity itself' (CARVALHO, 1996, p. 315). A poupança não pode financiar o investimento, pelo fato de a poupança ser a resultante da variação de renda produzida pela variação inicial do investimento: é impossível financiar esse investimento inicial a partir de um valor que não existe quando esse investimento é realizado. Assim, o investimento não pode depender de uma poupança prévia ${ }^{4}$ (CHICK, 1991, p. 192; CARVALHO, 1997, p. 468).

$\mathrm{Na}$ tradição clássica, ao contrário, o ajustamento se dá a partir de uma variação da taxa de juros, com esse movimento explicando a convergência sistemática para a taxa natural de juros. É igualmente importante observar que, na TFE, investimento e

\footnotetext{
4 A este respeito, ver a abordagem de Cardim (CARVALHO, 1992b, p. 108) no que diz respeito ao finance motive.
} 
poupança são determinados a partir da mesma variável (a taxa de juros) e que essa taxa de juros é, ela mesma, determinada pela poupança e pelo investimento.

$\mathrm{Na}$ TG, a taxa de juros é determinada exogenamente pela preferência pela liquidez (PL), a partir do seguinte mecanismo: a PL determina a demanda por moeda, a qual explica, num segundo momento, as variações da taxa de juros necessárias para igualar, novamente, demanda e oferta por moeda (KEYNES, 1990[1936], p. 137). Existe assim uma determinação monetária da taxa de juros, com esta sendo determinada, em última instância, pela PL.

No modelo neoclássico, ao contrário, a taxa de juros determina a demanda por moeda e é concebida como o custo de oportunidade de se reter moeda (FRIEDMAN, 1974, p. 25); quanto maior é esse custo, menor é a demanda por moeda. Por outro lado, o fato de a taxa de juros ser igual, na posição de equilíbrio, à produtividade marginal do capital, a qual é igual à taxa de lucro, no modelo neoclássico, não permite deduzir, como o faz Jevons, que a taxa de juros é determinada pela produtividade marginal do capital (DENIS, 1974, p. 499). Encontramos, novamente, a crítica de Keynes à TFE:

i) Taxa de juros e produtividade marginal do capital (eficiência marginal do capital, na TG) são determinadas de maneira independente: a taxa de juros depende da incerteza e da PL, a eficiência marginal do capital, das expectativas de longo prazo dos empresários e do preço de oferta.

ii) A igualdade entre taxa de juros e eficiência marginal do capital caracteriza apenas a posição de equilíbrio, na qual o retorno previsto do último investimento realizado é igual à taxa de juros. A taxa de juros é determinada exogenamente e sem nenhuma relação com a eficiência marginal do capital, ${ }^{5}$ a partir de mecanismos institucionais e/ou da avaliação que os agentes fazem da incerteza.

A análise de Keynes, na TG, nega a relação de causalidade neoclássica; essa negação ressalta a determinação monetária da taxa de juros e o fato de a moeda determinar o investimento, ou seja, a esfera real. De fato, a causalidade do modelo neoclássico é a seguinte: o investimento e a poupança determinam a taxa de juros (a partir da TFE), a qual determina a demanda por moeda. Ao contrário, na TG, a PL determina a demanda por moeda e esta determina a taxa de juros. Assim, na teoria neoclássica, a demanda por moeda é determinada pela taxa de juros, enquanto na TG a taxa de juros é determinada pela demanda por moeda, ou seja, pela PL.

\footnotetext{
Concordo assim plenamente com Pasinetti quando ele afirma que: "se a taxa de juros determina o investimento, a recíproca não é verificada" (1997, p. 209).
} 
Contrariamente à interpretação de Hicks (o modelo IS/LM), a PL não é uma simples demanda por moeda, mas um determinante fundamental da taxa de juros: "liquidity preference, even narrowly understood, is not a theory of demand for money but a theory of interest rate" (CARVALHO, 1992b, p. 97).

\subsection{PREFERÊNCIA PELA LIQUIDEZ E MOEDA OCIOSA: AS AMBIGUIDADES PRESENTES NA TG}

No esquema keynesiano, a taxa de juros não equilibra poupança e investimento no nível que corresponde ao pleno emprego, mas permite igualar "o desejo de manter a riqueza em forma líquida" com a oferta de moeda exógena determinada, por hipótese, pelo Banco Central (KEYNES, 1990[1936], p. 37). A PL se explica pelo fato de a moeda cumprir a função de reserva de valor: ela propicia para seus detentores uma segurança diante da incerteza, no sentido definido por Keynes.

A demanda por moeda depende de três motivos: transação e precaução $\left(\mathrm{L}_{1}\right)$, os quais dependem da renda; e especulação $\left(\mathrm{L}_{2}\right)$, que depende, de maneira inversa, da taxa de juros. Enquanto a demanda de moeda que depende diretamente da renda implica na neutralidade da moeda, apenas a demanda de moeda por motivo de especulação explicaria sua relação com a incerteza; as expectativas relativas às evoluções da taxa de juros seriam, assim, a principal fonte de incerteza.

O equilíbrio no mercado da moeda verifica a seguinte equação:

$$
\mathrm{L}=\mathrm{L}_{1}(Y)+\mathrm{L}_{2}(r)
$$

Em (3), L representa a oferta de moeda; $\mathrm{L}_{1}$ corresponde à demanda de moeda por motivo de transação e precaução e $\mathrm{L}_{2}$, à demanda de moeda por motivo de especulação

As ambiguidades provêm do fato que, para Keynes, a demanda de moeda por motivo de precaução depende da renda e não da incerteza. É preciso questionar essa abordagem e explicitar as diferentes modalidades segundo as quais a incerteza se manifesta: (i) o motivo de transação se relaciona com a esfera "real" e expressa a neutralidade da moeda (CARVALHO, 2010, p. 718); e (ii) o motivo de precaução é definido como “ (...) o desejo de segurança com relação ao equivalente monetário futuro de certa parte dos recursos totais” (KEYNES, 1990[1936], p. 139, grifo meu). A definição dada por Keynes é particularmente ambígua: por um lado, o motivo de precaução é definido em função da incerteza, mas, por outro lado, a demanda de moeda ligada a esse motivo depende da renda: "[ $t]$ his meant minimising the more revolutionary elements of his theory, the demand for money as a defense against uncertainty" (CARVALHO, 2010, p, 717). 
Essa definição é contraditória, já que a demanda de moeda por motivo de precaução é definida em função da renda e não em função da incerteza. Kahn (1972) ressalta essa contradição e relaciona o motivo de precaução com a incerteza, e mais precisamente com a incerteza ligada à demanda de moeda por motivo de especulação.

Esse componente da demanda por moeda funciona a partir do seguinte mecanismo: se, em $t$, os especuladores esperam, em $t+1$, um aumento da taxa de juros, eles esperam uma diminuição do valor do título financeiro em $t+1$. Em $t$, a demanda de moeda por motivo de especulação $\left(\mathrm{L}_{2}\right)$ vai diminuir, pelo fato de que eles quererem comprar o título em $t+1$. A preferência pela liquidez vai aumentar em $t$ : uma vez que os especuladores têm que realizar uma escolha entre a compra de título e a posse de moeda, eles vão escolher a moeda em $t$. O motivo de precaução se define em função da incerteza relativa às variações da taxa de juros. Os agentes constituem um estoque de moeda ociosa que permite postergar a compra de títulos financeiros.

O motivo de especulação se define a partir do conceito de grau de confiança. As expectativas dos especuladores são mais "confiáveis": elas lhes permitem conhecer antes dos outros agentes as variações futuras da taxa de juros (KEYNES, 1990[1936], p. 129). Os especuladores vão realizar lucros por comprarem o título quando seu valor é baixo e vendê-lo quando seu valor é alto (HERSCOVICI, 2019).

In other words, the precautionary demand has to do with the possibility of change, while the speculative motive is a bet on a certain direction of change. Kahn's own approach was to make the speculative demand for money a definite bet on the direction of change in future interest rates, to be affected by the confidence with which the wealth-holder entertains this expectation of change. (CARVALHO, 2010, p. 175)

A dinâmica da especulação pode ser explicada a partir das assimetrias de informação que existem entre os diferentes grupos de agentes: os especuladores são aqueles que têm condições de “(...) prever com alguns meses de antecedência as bases da avaliação convencional ” (KEYNES, 1990[1936], p. 129). Isso se explica pelo fato de eles terem condições de prever antes dos outros agentes as variações futuras da taxa de lucro.

A probabilidade de os agentes menos informados preverem essas evoluções é menor. A partir de um comportamento mimético, eles vão imitar, com umas defasagens temporais, a atuação dos agentes informados; os ganhos realizados pelos especuladores se explicam exatamente a partir dessa defasagem temporal. ${ }^{6}$

6 Para uma análise detalhada desse mecanismo, ver Herscovici (2019). 
Esse diferencial de confiança entre os especuladores (ou seja, os informados) e o "grande público" - os agentes não ou pouco informados na terminologia utilizada por Grossman e Stigitz (1980) - dá conta do mecanismo ressaltado por Kahn (1972): por natureza, o erro cometido pelos especuladores, no que diz respeito à elaboração de suas expectativas, será sempre menor que aquele cometido pelo "grande público"?

Tanto os especuladores quanto o "grande público" podem querer guardar moeda para comprar, "mais tarde", títulos financeiros. Não obstante, em função do efeito de imitação, os especuladores compraram o título antes do grande público; em outras palavras, a demanda de moeda, por parte dos especuladores, tem por objetivo a compra de títulos num prazo menor do que o previsto pelo grande público.

Os dois motivos (precaução e especulação) estão interligados, na dinâmica especulativa: a moeda pode ser demandada para conservar um valor, ou ao contrário, para comprar imediatamente ativos. A escolha será feita em função do grau de confiança de cada grupo de agentes em suas expectativas. Conforme afirma Kahn (1972), em um determinado período, é impossível determinar qual é a parte da moeda ociosa que corresponde ao motivo de precaução e ao motivo de especulação. Considerando que o motivo de especulação se explica pelo fato de demandar uma quantidade de moeda em função da compra (imediata, ou quase imediata) de um determinado ativo, a parte da demanda de moeda que, em função das expectativas dos agentes, é destinada à compra de ativos, no futuro mais distante, será conservada, tendo em vista sua função de reserva de valor. Em todos os casos, trata-se de uma moeda "ociosa" cujo objetivo não consiste na compra imediata de bens e serviços.

Por outro lado, não acredito que a PL possa ser definida unicamente em função das atividades ligadas à especulação; a PL é igualmente determinada a partir do investimento produtivo. Para Keynes, o investimento produtivo é uma decisão que se relaciona com o longo prazo. Keynes utiliza uma concepção marshalliana, na qual o curto prazo se caracteriza por um estoque constante de capital e o longo prazo pela variação desse estoque de capital (CARVALHO, 1990). As expectativas de curto prazo podem ser revistas a curto prazo, e "substituídas pelos resultados realizados" (1990[1936], p. 56): Keynes desconsidera a incerteza no curto prazo e, consequentemente, a incerteza se manifesta essencialmente no longo prazo. Por outro lado, Keynes afirma que "não faz parte da natureza das expectativas a longo prazo poderem ser revistas a curtos intervalos de tempo à luz dos resultados realizados" (ibidem). Uma vez o investimento realizado na base de determinadas expectativas de

\footnotetext{
Keynes estabelece esta distinção: a respeito dos agentes pouco ou não informados, ele fala em "psicologia de massa de indivíduos ignorantes" (1990[1936], p. 128).
} 
longo prazo, ele constitui um custo irreversível para o empresário, mesmo se essas expectativas não se realizam nos próximos períodos.

O conceito de incerteza forte, da maneira como ele foi definido por Keynes (1935) depende diretamente do caráter irreversível do investimento. No universo definido pela economia neoclássica, não existe incerteza. Essa ausência de incerteza se justifica a partir da ausência de custos irreversíveis: na tradição marshalliana, no mercado de concorrência pura e perfeita, há livre entrada e livre saída na indústria - na teoria dos mercados contestáveis de Baumol (1982), por exemplo, uma das condições para que os mercados sejam contestáveis é que não haja barreiras à saída.

Ao contrário, no que diz respeito à finança especulativa, o investimento especulativo é considerado reversível, pelo fato de se relacionar com o curto prazo. A esse respeito, Keynes afirma que o especulador tem "a oportunidade de rever suas decisões e modificar o investimento antes que haja tempo para que ocorram grandes alterações"; esses investimentos que são "fixos" para a comunidade e tornam-se "líquidos" para o indivíduo" (1990[1936], p. 127).

Assim, a PL não pode ser limitada às atividades especulativas; ela se relaciona igualmente com os setores produtivos, e com as relações entre este, a moeda e a finança. A escolha dos ativos é realizada entre ativos produtivos, moeda e finança.

\section{FINANÇA ESPECULATIVA, EFEITOS DE PROPAGAÇÃO E NÃO NEUTRALIDADE DA FINANÇA}

\subsection{FINANÇA PRODUTIVA VERSUS FINANÇA ESPECULATIVA}

Keynes diferencia explicitamente duas lógicas financeiras: o empreendimento que chamarei de finança produtiva e a especulação, que denominarei finança especulativa (1990[1936], p. 131).

Um determinado título financeiro (no caso, uma obrigação) é emitido no mercado primário. O retorno que provém da taxa de juros é calculado em função do valor de emissão, para uma duração fixa. Trata-se da finança produtiva: (i) seu retorno é certo, e determinado ex ante pela taxa de juros aplicada no valor de emissão do título financeiro; (ii) é um mecanismo de financiamento que atua no longo prazo; e (iii) esse mecanismo está diretamente conectado com as atividades produtivas (KEYNES, 1990[1936], p. 131; HERSCOVICI, 2017; ORLÉAN, 2011, p. 267).

Ao contrário, o retorno próprio à finança especulativa provém principalmente das evoluções do valor desse título nos mercados secundários. A especulação consiste em comprar o título quando seu valor está baixo e vendê-lo quando este valor está alto. $\mathrm{O}$ 
retorno provém, principalmente, da mais-valia financeira realizada pelo especulador: o especulador "somente na expectativa de um ganho de capital está disposto a adquirir um título" (KEYNES, 1990[1936], p. 131). A finança especulativa apresenta as seguintes características: (i) seu retorno depende diretamente da variação do valor do título; (ii) é um mecanismo de curto prazo que se explica a partir das assimetrias de informação existentes entre os diferentes grupos de agentes (HERSCOVICI, 2019); e (iii) ela é totalmente desconectada do setor produtivo.

Segundo o próprio Keynes, o equilíbrio é realizado quando podemos verificar a seguinte relação (1990[1936], p. 177 e seguintes):

$$
q_{1}+a_{1}=a_{2}=l_{3}
$$

Em (4), q representa o rendimento do ativo; $a$ representa a variação de seu valor durante o período considerado, e $l$ representa o prêmio de liquidez.

A relação (4) estabelece uma comparação entre o retorno de três ativos, o primeiro sendo um ativo produtivo, o segundo um ativo especulativo e o terceiro a moeda. Se um desses ativos apresenta um retorno maior que os outros, haverá uma transferência para o ativo que apresenta o retorno maior, até voltar a verificar novamente (4). Esses efeitos de propagação se traduzem por um mecanismo de ajuste de portfólio, o que faz com que é impossível determinar a parte dos créditos bancários destinada à circulação financeira e aquela destinada à circulação industrial (CARVALHO, 2005, p. 328 e 330): o sistema bancário deixa de ser neutro, em relação ao setor produtivo, e assume assim um papel ativo na especulação financeira. Em outras palavras, contrariamente ao que afirma a teoria ortodoxo, o papel dos bancos não consiste unicamente em financiar as atividades do setor produtivo.

A intensificação da financeirização, ou seja, das atividades que se relacionam com o que eu defini como finança especulativa, tem por efeito igualar o retorno de cada investimento, para poder verificar a relação (4). Isso se traduz por um aumento da taxa de retorno $\left(r^{*}\right)$ utilizada para poder realizar o investimento produtivo e, consequentemente, por uma queda dos investimentos produtivos cujas eficiências marginais são inferiores a esta taxa de retorno.

A função de investimento utilizada por Keynes pode ser escrita da seguinte maneira:

$$
I=\varphi\left(e-r^{*}\right)
$$

$\operatorname{com} \phi^{\prime}>0$

Em (5), $e$ representa a eficiência marginal do capital e $r^{*}$ a taxa de retorno mínima exigida. 
Como a financeirização se traduz por um aumento de $r^{*}$, vários investimentos que poderiam ser realizados com um retorno mais baixo deixam de ser realizados (PASINETTI, 1997). A transferência dos ativos produtivos para os especulativos se traduz por uma queda da produção e do nível de emprego; as elasticidades de produção desses ativos especulativos sendo particularmente fracas, o emprego perdido no setor produtivo não é compensado pelo emprego criado no setor ligado à especulação.

\subsection{PREFERÊNCIA PELA LIQUIDEZ E INCERTEZA}

A demanda por moeda é composta por moeda ativa e moeda ociosa: a moeda ativa se relaciona diretamente com a compra e/ou o financiamento dos ativos, sejam eles produtivos ou financeiros. A moeda "ociosa" consiste em reter moeda para postergar a compra, tendo em vista que a moeda permite conservar o valor no tempo. Em outras palavras, a PL se relaciona diretamente com a incerteza ligada ao investimento produtivo ("real") e ao investimento especulativo.

Em função dessas observações, é preciso reescrever a relação que expressa o equilíbrio no mercado da moeda da seguinte maneira:

$$
\mathrm{L}=\mathrm{L}_{1}(\mathrm{Y})+\mathrm{L}_{2}(\mathrm{r})+\mathrm{L}_{3}\left(\Omega_{1}\right)+\mathrm{L}_{4}\left(\Omega_{2}\right)
$$

Em (6), $\Omega_{1}$ representa a incerteza ligada ao investimento produtivo e $\Omega_{2}$ a incerteza própria ao investimento especulativo; $\mathrm{L}_{1}$ e $\mathrm{L}_{2}$ representam os componentes de moeda ativo, pelo fato de representarem uma demanda por moeda que corresponde a gastos realizados "hoje"; $\mathrm{L}_{3}$ e $\mathrm{L}_{4}$ representam a moeda ociosa, destinada a postergar a compra de ativos produtivos e financeiros, em função da incerteza e das expectativas relativas às evoluções da taxa de lucro.

A partir das relações construídas precedentemente, é possível afirmar que esses componentes são interdependentes. Por exemplo, uma diminuição exógena de $r$ tem as seguintes implicações: um aumento de $\mathrm{L}_{2}$, em função das expectativas relativas ao valor dos títulos, e um aumento de $\mathrm{L}_{1}$, em função do aumento do investimento e do aumento resultante do produto e do emprego. Intuitivamente, quando está havendo uma queda da taxa de juros, uma quantidade maior de capitais se torna rentável, o que pode ser interpretado como uma diminuição da incerteza ligada ao investimento produtivo, e consequentemente, como uma diminuição de $\mathrm{L}_{3}$.

Um aumento da massa monetária terá um efeito positivo sobre o produto apenas se ele for superior ao aumento da demanda: em função de (6), essa condição será verificada apenas se os efeitos do aumento da massa monetária não forem neutralizados 
pelo aumento de $\mathrm{L}_{1}$, $\mathrm{L}_{2}$ e pela diminuição de $\mathrm{L}_{3}$ : “[e]mbora seja de esperar que, ceteris paribus, um aumento na quantidade de moeda reduza a taxa de juros, isto não ocorrerá se a preferência do público aumentar mais que a quantidade de moeda" (KEYNES, 1990[1936], p. 141).

O desenvolvimento da especulação financeira implica uma intensificação da incerteza que pesa sobre o investimento produtivo: enquanto a liquidez desse tipo de investimento é, por natureza, limitada, a liquidez relativa ao investimento especulativo é elevada. A partir dessa liquidez, é possível explicar seus retornos. Assim, quanto maior for a liquidez dos investimentos especulativos, maiores serão as variações do valor dos títulos e maior será a incerteza relativa aos investimentos produtivos.

Esse mecanismo está implícito na própria definição do preço de oferta:

$$
P o=\Sigma Q i /(1+e)^{n}
$$

Em (7), Po representa o preço de oferta; $Q i$ representa as expectativas de receitas; $e$ é a eficiência marginal do capital e $n$, a vida útil do investimento.

A relação (7) mostra claramente que a um aumento da taxa de atualização escolhida corresponde uma diminuição de $P o$, para $\Sigma Q i$ constante. O preço de oferta se relaciona com "a taxa de retorno que se espera obter do dinheiro investido num bem recentemente produzido; e não do resultado histórico obtido por um investimento em relação a seu custo original, quando examinado retrospectivamente ao fim de sua vida" (KEYNES, 1990[1936], p. 115, grifo no original).

Por outro lado, a liquidez de um determinado ativo se define pelo fato de seu valor ser garantido no tempo (CARVALHO, 1992a, p. 184). Assim, quanto maior for a instabilidade da taxa de atualização escolhida, conforme ressaltado na relação (7), maior será a incerteza relativa à determinação do preço de oferta do ativo; sua liquidez varia, sua irreversibilidade se acentua, o que corresponde a uma intensificação da incerteza ligada a este tipo de ativo. Consequentemente, $\mathrm{L}_{3}$ aumenta.

O início de uma crise se caracteriza, geralmente, por um aumento da taxa de juros, o que provoca inicialmente uma crise financeira e um processo cumulativo de queda do valor dos títulos (HERSCOVICI, 2019). Isso se traduz por uma queda de $\mathrm{L}_{1}$ e $\mathrm{L}_{2}$ e por um aumento de $\mathrm{L}_{3}$ e $\mathrm{L}_{4}$. Os efeitos de propagação se desenvolvem quando o aumento de $\mathrm{L}_{3}$ e $\mathrm{L}_{4}$ se torna superior à queda de $\mathrm{L}_{1}$ e $\mathrm{L}_{2}$.

\subsection{EFEITOS DE PROPAGAÇÃO E NATUREZA DO SISTEMA BANCÁRIO}

Existe assim um mecanismo de propagação no que diz respeito à elevação da taxa de retorno provocada pela intensificação da financeirização. Como, por natureza, a 


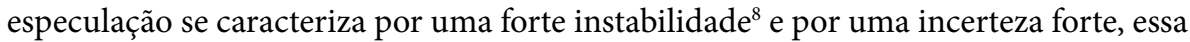
instabilidade repercutirá nos investimentos realizados no setor produtivo. À essa instabilidade financeira corresponde uma instabilidade da taxa de retorno mínima que os investimentos produtivos têm que alcançar.

Consequentemente, essa análise permite ressaltar a natureza desses mecanismos de propagação: a instabilidade de curto prazo própria às atividades especulativas determina as condições de viabilização econômica dos investimentos realizados, no longo prazo, no setor produtivo. ${ }^{9} \mathrm{O}$ conjunto do sistema econômico é objeto de fragilidade financeira à la Minsky: o desenvolvimento das atividades financeiras ligadas à especulação implica que uma parte crescente dos investimentos produtivos de longo prazo seja financiada por capitais cujo valor é particularmente instável, e cuja permanência é relativamente curta, tanto no curto quanto nolongo prazo (CARVALHO, 1997, p. 484).

Esse efeito de propagação depende diretamente do grau de desenvolvimento da finança especulativa:

(...) na ausência de um mercado organizado, a preferência pela liquidez, devida ao motivo de precaução, aumentaria muito, ao passo que a existência de um mercado organizado proporcionaria a oportunidade de amplas flutuações da preferência pela liquidez, devida ao motivo de especulação. (KEYNES, 1990[1936], p. 139)

Um mercado organizado é constituído pelos mercados secundários nos quais os títulos financeiros são negociados, depois de terem sido emitidos no mercado primário (CARVALHO, 2016, p. 301). Quanto mais desenvolvidos forem esses mercados secundários, maiores serão as oportunidades de especulação, ou seja, de venda e de compra desses títulos, e maiores serão as possibilidades de realizar ganhos em função das variações do valor desses títulos; consequentemente, maiores serão as flutuações da PL devidas ao motivo de especulação.

8 A esse respeito, Cardim afirma que a abordagem pós-keynesiana "takes instability as a process, a normal feature of the workings of the financial system" (CARVALHO, 2009).

9 É preciso ressaltar o fato de que as expectativas de curto prazo determinam, pelo menos parcialmente, as expectativas de longo prazo: trata-se de path dependence, o que implica (a) que o sistema não converge rumo a um equilíbrio de longo prazo predeterminado e (b) que haja uma determinação, pelo menos parcialmente endógena das expectativas de longo prazo (HERSCOVICI, 2019). Por outro lado, isso corresponde ao fato que "[ $w]$ hat matters is the long-term expectations rather than long-period values" (CARVALHO, 1990, p. 288). 
Na perspectiva de Keynes, o desenvolvimento da finança se dá em detrimento do investimento produtivo, pelo fato de "puxar" $r^{*}$ para cima e de eliminar assim os investimentos cuja eficiência marginal é inferior a esta mesma taxa de retornos "[u]ma baixa violenta no preço das ações (...) produz um efeito desastroso sobre a eficiência marginal do capital (...) [e] pode ser provocada pelo enfraquecimento (...) da confiança especulativa” (1990[1936], p. 131). Existe obviamente um mecanismo de propagação da esfera especulativa para a esfera real; o motivo de especulação determina uma certa $P L$, essa última determina o nível da taxa de juros e, consequentemente, o nível do investimento e do emprego.

Keynes considera diferentes situações às quais correspondem efeitos de propagação diferenciados: ${ }^{10}$ quando a especulação é pouco desenvolvida, a demanda de moeda por motivo de especulação é fraca. Nesse caso, um aumento da massa monetária se traduz por uma queda da taxa de juros e por um aumento do investimento e do emprego (1990[1936], p. 140). Se, ao contrário, a especulação for importante, o aumento da massa monetária será absorvido pelo aumento da PL dos especuladores e não terá impacto sobre o produto e o nível do emprego. ${ }^{11}$ A elasticidade da taxa de juros, em relação às variações da massa monetária e, consequentemente, os efeitos provocados pelo aumento dessa massa, dependem do peso relativo da especulação na economia: quanto maior for esse peso, menor serão os efeitos em termos de variação da renda e do emprego.

Finalmente, no âmbito de uma perspectiva pós-keynesiana, é possível mostrar que o desenvolvimento da especulação se traduz por uma intensificação das desigualdades da renda (DÁVILA et al., 2017; HERSCOVICI, 2019); isso implica obrigatoriamente em uma diminuição do multiplicador de investimento e, consequentemente, em uma diminuição dos efeitos de uma política fiscal.

À medida que a bolsa de valores realiza reavaliações diárias do valor das empresas, as expectativas de curto prazo dos especuladores "exercem uma influência decisiva sobre o montante do investimento corrente" (KEYNES, 1990[1936], p. 126). Estamos na presença de uma financial governance na qual as expectativas de retorno do investimento produtivo são determinadas "pela expectativa média dos que negociam na bolsa de valores." (idem, p. 126). No caso de uma bolha financeira, as expectativas de retorno são particularmente elevadas, o que se traduz por um desvio da demanda para os ativos financeiros e por uma rejeição dos investimentos que não têm condições de auferir um retorno que corresponda a essas expectativas.

\footnotetext{
${ }^{10}$ A síntese neoclássica realizada a partir dos trabalhos de Hicks privilegiou esses mecanismos, ignorando características fundamentais do universo de Keynes: a incerteza forte e as assimetrias entre os agentes, entre outras. No que diz respeito aos limites das tentativas de integração neoclássica da TG, ver, por exemplo Cardim (CARVALHO, 1992a, 1988a).

11 Isso corresponde à armadilha à liquidez, na síntese neoclássica.
} 
Por outro lado, os mercados financeiros são particularmente instáveis, o que significa que a incerteza é grande; isso se traduz por um aumento da preferência pela liquidez, da taxa de juros e, consequentemente, por uma queda do investimento produtivo.

O desenvolvimento da finança especulativa tem por efeito reduzir a eficiência das políticas monetárias: à medida que o aumento da massa monetária for absorvido pela demanda de moeda por motivo de especulação, ela não se traduz por um aumento do produto nem do emprego. Os efeitos dessa política vão diretamente depender da estrutura da demanda por moeda, ou seja, dos componentes ligados à circulação financeira e daqueles ligados à circulação industrial (CARVALHO, 2005, p. 330 e 331).

Finalmente, à medida que a elasticidade de produção dos títulos financeiros e da moeda é próxima de zero, uma transferência da demanda para esses ativos tem por consequência direta uma queda do volume de emprego. É assim possível afirmar que, em função dessa transferência de renda dos trabalhadores para os especuladores, $o$ desenvolvimento dos mercados financeiros diminui o valor do multiplicador de gastos e reduz assim os efeitos positivos das políticas econômicas.

A respeito da função de emprego, Keynes diferencia as indústrias em função de suas elasticidades de emprego e de suas elasticidades de produção (1990[1936], p. 220 e 221). Essas elasticidades medem a variação do emprego e as variações da produção que resultam de uma variação inicial da demanda efetiva. A elasticidade de emprego é definida pela seguinte equação:

$$
e_{e r}=\frac{d N r}{N r} / \frac{d D w r}{D w r}=\frac{d N r}{d W r} \cdot \frac{D w r}{N r}
$$

Já a elasticidade da produção é definida por:

$$
e_{o r}=\frac{d O r}{O r} / \frac{d D w r}{D w r}=\frac{d O r}{d W r} \cdot \frac{D w r}{O r}
$$

Nessas equações, $\mathrm{Nr}$ representa o volume de emprego; $D w r$ representa a demanda; e $O r$ corresponde à oferta; já $d$ indica a variação.

Keynes afirma que "se a demanda adicional se dirige aos produtos que têm uma elasticidade relativamente baixa de emprego, uma proporção maior dessa demanda irá aumentar as rendas dos empresários" (1990[1936], p. 225); o desenvolvimento desses mercados produz um efeito limitado, em termos de nível de emprego.

As atividades ligadas à finança especulativa apresentam as seguintes características: suas elasticidades de emprego e de produção são baixas. $\mathrm{O}$ ajustamento realizado nesses mercados se implementa principalmente a partir de uma variação dos preços, e 
não das quantidades produzidas. A oferta desse tipo de ativos é, por natureza, limitada (TIROLE, 2016, p. 407): no caso contrário, o aumento da demanda implicaria em um aumento dos preços, o qual implicaria em um aumento da oferta e em uma diminuição posterior dos preços, o que limitaria fortemente as variações do valor dos títulos e, consequentemente, a especulação. A limitação da oferta constitui uma das condições a partir das quais a finança especulativa pode se desenvolver; essa rigidez da oferta é uma das características dos mercados nos quais os bens e os capitais são fortemente heterogêneos (HERSCOVICI, 2017), e os ajustamentos se realizam principalmente a partir de uma variação dos preços, e não das quantidades.

Essa análise nos leva a definir a função e a natureza do sistema bancário. Da mesma maneira que a análise neoclássica adota a hipótese de neutralidade da moeda, ela adota, implicitamente, a hipótese da neutralidade da finança. O sistema de crédito constitui um simples intermediário entre poupadores e investidores e apenas corresponde à concretização da TFE, à medida que ele permite implementar concretamente o mercado no qual a demanda por fundos encontra a oferta por fundos.

Banks further complicated the relationship between saving and investment but again they were not allowed to change its ultimate nature. Bank deposits and loans dealt with the means to purchase the goods that are going to be accumulated. The possibility of accumulation continued to depend on the desire of income earners to save and of investors to invest. (CARVALHO, 2012, p. 201)

Essa neutralidade se manifesta da seguinte maneira: nas análises em termos de expectativas racionais, as bolhas especulativas são concebidas como um desvio em relação ao valor fundamental desses títulos; a bolha estoura quando esse desvio ultrapassa um determinado valor limite (FAMA, 1998; MALKIEL, 2003, TIROLE, 2016). Esse valor fundamental é definido no setor real, a partir das expectativas de lucro da empresa que lançou esses títulos no mercado: esse valor fundamental se define como "o valor atualizado dos dividendos, juros e alugueis que o título propiciará hoje e no futuro" (TIROLE, 2016, p. 404-405).

Essa abordagem mantém os postulados da análise neoclássica: (i) a análise é realizada em termos reais, o que significa que, no longo prazo, a moeda e a finança não influenciam os movimentos reais; (ii) a existência da finança especulativa é, por princípio, negada, à medida que não existem assimetrias de informação entre os diferentes agentes que atuam nesses mercados e que, consequentemente, o único ganho realizado nesses mercados é aquele que corresponde aos dividendos e juros; (iii) o postulado de ergodicidade é adotado, pelo fato dos agentes poderem prever os retornos dos títulos durante toda sua existência: não há incerteza forte (CARVALHO, 1998b). 
A análise pós-keynesiana é incompatível com esses resultados: a partir da parábola do concurso de beleza (KEYNES, 1990[1936], p. 129), ela refuta a existência de um valor fundamental dos títulos. Ela mostra, ao contrário, que este valor é determinado a partir de um mecanismo de autorrealização das profecias (ORLÉAN, 2011). Por outro lado, a dinâmica deste mecanismo se explica a partir da existência de assimetrias da informação. É preciso acrescentar que a existência de incerteza, a qual justifica a PL, entra diretamente em conflito com o postulado de ergodicidade.

Em um nível empírico, não é possível considerar que os depósitos realizados no seio do sistema bancário são unicamente destinados à compra de investimentos produtivos, conforme pressupõe a análise neoclássica: "it is difficult to separate the precautionary from the speculative motives since both deal with inactive balances, where money is held as an asset instead of a means of payment held in anticipation of planned expenditures" (CARVALHO, 2010, p. 778). Simetricamente, isso implica que os créditos concedidos pelos bancos não são unicamente destinados ao financiamento do investimento produtivo; eles podem servir a financiar um investimento especulativo, ou a se prevenir contra a incerteza, sob a forma de constituição de moeda ociosa: "one may plan to take credit for the purchase of old assets, i.e. for financial investment. This has nothing to do with the new investment of the industrial sphere, which is related to savings" (CARVALHO, 2012, p. 202).

No sistema keynesiano, nem a moeda nem a finança são neutras. A moeda retida no sistema bancário não se relaciona unicamente com as atividades transacionais (concepção tradicional dos motivos de transação e precaução), mas também com a moeda ociosa e com a moeda ligada às atividades especulativas.

\section{CONCLUSÃo}

É importante ressaltar as diferenças que existem entre esta interpretação e aquela proposta pela síntese neoclássica: na interpretação que construí aqui, incorporei os elementos fundamentais que caracterizam o núcleo duro da teoria pós-keynesiana, principalmente a incerteza forte, a refutação da TFE e a teoria das escolhas dos ativos em um universo que se caracteriza pela incerteza forte. Esses elementos são ausentes na síntese neoclássica: (i) a demanda de moeda por motivo de especulação não é determinada em função da incerteza; (ii) conforme ressalta o eviction effect, por exemplo, a taxa de juros é determinada endogenamente, a partir dos diferentes investimentos; e (iii) a poupança financia o investimento, o que é totalmente incompatível com os mecanismos ressaltados na TG.

A análise elaborada neste trabalho é totalmente coerente com o universo descrito na TG: (i) não existe dicotomia entre a esfera real, a esfera monetária e a esfera 
financeira; (ii) a moeda cumpre um papel de reserva de valor; e (iii) a taxa de juros é determinada pela oferta de moeda, pelas expectativas ligadas à finança especulativa e pela incerteza que caracteriza o investimento produtivo, ou seja, pela PL global. Aparecem assim as limitações das diferentes modalidades de integração dos resultados keynesianos na matriz neoclássica.

A ruptura fundamental entre Keynes e a economia clássica é realizada nos capítulos XIII e XIV da TG: nesses capítulos, Keynes ressalta a natureza monetária e financeira da taxa de juros, em oposição à sua natureza real, na economia clássica. Após ter redefinido, em função das ambiguidades presentes na TG, os diferentes componentes da PL, pode estudar os mecanismos de propagação que ressaltam as relações orgânicas de interdependência entre as esferas monetária, financeira e real. À não neutralidade da moeda, é preciso acrescentar a não neutralidade do sistema financeiro; é uma das principais conclusões deste trabalho, conclusões obtidas a partir de uma redefinição da demanda de moeda por motivo de precaução.

\section{REFERÊNCIAS BIBLIOGRÁFICAS}

BAUMOL, W. J. Contestable markets: an uprising in the theory of industry structure. American Economic Review, v. 72, n. 1, p. 1-15, Mar. 1982.

CARVALHO, F. J. C. Da síntese neoclássica à redescoberta de Keynes. Análise Econômica, ano 6, n. 9, p. 3-21, 1988(a).

CARVALHO, F. J. C. Keynes on probability, uncertainty, and decision-making. Journal of Post Keynesian Economics, v. 11, n. 1, p. 66-180, 1988(b).

CARVALHO, F. J. C. Keynes and the long period. Cambridge Journal of Economics, v. 14, n. 3, p. 277-290, 1990.

CARVALHO, F. J. C. Moeda, produção e acumulação: uma perspectiva keynesiana. In: FALCÃO SILVA, M. L. (Org.). Moeda e produção: teorias comparadas. Brasília, DF: Editora da Universidade de Brasília, 1992a, p. 113-127.

CARVAlHO, F. J. C. Mr Keynes and the Post-Keynesians. Principles of Macroeconomics for a monetary production economy. London: Edward Elgar, 1992b.

CARVALHO, F. J. C. Sorting out the issues: the two debates (1936/37; 1983-86) on Keynes's finance motive revisited. Revista Brasileira de Economia, v. 50, n. 3, p. 312-327, 1996.

CARVALHO, F. J. C. Financial innovation and the Post Keynesian approach to the 'process of capital formation'. Journal of Post Keynesian Economics, v. 19, n. 3, p. 461-487, 1997.

CARVALHO, F. J. C. Uma contribuição ao debate em torno da eficácia da política monetária e algumas implicações para o caso do Brasil. Revista de Economia Política, v. 25, n. 4, p. 323 336, 2005.

CARVALHO, F. J. C. Systemic crisis, systemic risk and the financial instability hypothesis. 2009. Mimeo. 
CARVALHO, F. J. C. Uncertainty and money: Keynes, Tobin and Kahn and the disappearance of the precautionary demand for money from liquidity preference theory. Cambridge Journal of Economics, v. 34, n. 4, p. 709-725, 2010.

CARVALHO, F. J. C. Aggregate savings, finance and investment. Intervention, v. 9, n. 2, p. 197213, 2012.

CARVALHO, F. J. C. Liquidity preference and monetary economics. London: Routledge, 2015.

CARVALHO, F. J. C. On the nature and role of financial systems in Keynes's entrepreneurial economies. Journal of Post Keynesian Economics, v. 39, n. 3, p. 287-307, 2016.

CHICK, V. Macroeconomics after Keynes. A reconsideration of the General Theory. Cambridge, MA: MIT Press, 1991.

COHEN, A. J.; HARCOURT, G. C. Whatever happened to the Cambridge capital theory controversies? Journal of Economic Perspectives, v. 17, p. 199-14, Winter 2003.

DÁVILA-FERNÁNDEZ, M. J.; OREIRO, J. L.; PUNZO, L. F.; BIMONTE, S. Capital in the Twenty First Century: Reinterpreting the fundamental contradiction of capitalism. Journal of Post Keynesian Economics, p.168-182, 2017.

DENIS, H. Histoire de la Pensée Economique. Paris: Presses Universitaires de France, 1974.

FAMA, E. Market efficiency, long term returns and behavioral finance. Journal of Financial Economics, v. 49, n. 3, p. 283-306, Sept. 1998.

FRIEDMAN, M. A. Theoretical framework for monetary analysis. In: GORDON, R. J. (Ed.). Milton Friedman's monetary framework: a debate with his critics. Chicago: University of Chicago Press, 1974, p. 1-62.

GROSSMAN, S. J.; STIGLITZ, J. E. On the impossibility of informationally efficient markets. The American Economic Review, v. 70, n. 3, p. 393-408, Jun. 1980.

HAYEK, F. V. The pure theory of capital. Auburn, AL: The Ludwig von Mises Institute, 2009[1950].

HERSCOVICI, A. Keynes e o conceito de capital: reflexões epistemológicas a respeito das premissas sraffianas da Teoria Geral. Revista de Economia Política, v. 33, n. 3 (132), p. 486504, jul./set. 2013.

HERSCOVICI, A. Nature and implications of financialization: from quasi-competitive equilibrium to speculative dynamic. In: INTERNACIONAL CONFERENCE ON ECONOMIC THEORY AND POLICY, Meiji University, Tokyo, Japan, 15-17 Sept. 2017.

HERSCOVICI, A. Essays on the Historicity of Capital. New York: Palgrave Macmillan, 2019.

KAHN, R. Selected essays on employment and growth. Cambridge: Cambridge University Press, 1972, p. 72-96.

KEYNES, J. M. A teoria geral do emprego, do juro e da moeda. São Paulo: Atlas, 1990[1936].

KEYNES, J. M. Treatise on probabilities. In: Collected Writtings of J. M. Keynes. London: Mac Millan and Cambridge University Press, 1935, v. 8.

MALKIEL B. G. The efficient market hypothesis and its critics. Journal of Economic Perspectives, v. 17, n. 1, p. 59-82, 2003. 
ORLÉAN, A. L'empire de la valeur. Refonder l'Économie. Paris: Éditions du Seuil, 2011.

PASINETTI, L. L. The marginal efficiency of investment. In: HARCOURT, G. C.; RIACH, P. (Eds.). A "Second Edition" of the General Theory. London: Rouledge, 1997, v. 1, p. 185-197.

PETRI, F. The "Sraffian" critique of neoclassical economics: some recent developments. Revista da Sociedade Brasileira de Economia Política, n. 3, p. 5-44, dez. 1998.

SOLOW, R. M. A contribution to the theory of economic growth. Quartely Journal of Economics, v. 70, p. 65-94, 1956.

TIROLE, J. Economie du bien commun. Paris: PUF, 2016.

VERCELLI, A. Methodological foundations of macroeconomics: Keynes and Lucas. Cambridge: Cambridge University Press, 1991. 